\title{
Journalism in the era of mobile technology: The changing pattern of news production and the thriving culture of fake news in Pakistan and Ghana
}

\author{
Sadia Jamil ${ }^{1}$ \\ University of Queensland, Australia
}

Gifty Appiah-Adjei

University of Education, Winneba, Ghana

DOI: $10.30547 /$ worldofmedia.3.2019.2

\begin{abstract}
The advent of new technologies has resulted in the rise of mobile journalism around the globe. Mobile devices have reformed the newsroom environments by introducing new means to connect with the audience and to communicate with other journalists within the same place. Many traditional media organizations already produce news content for mobile web-sites and apps in proportion to cross-media strategies, reflecting structural changes in the journalism industry and transformation in the process of news production in many countries and although coming from different cultural traditions and geographical locations, Pakistan and Ghana are no exceptions. However, there are concerns about the potential role of mobile journalism in fostering the culture of fake news in both countries. Thus, using the media convergence and social responsibility theories, this study aims to analyse how mobile journalism is altering the news production process and fostering the trend of fake news in Pakistan and Ghana. To accomplish this aim, this study uses the qualitative methods of document review and in-depth interviews and offers a thematic analysis of the qualitative data.
\end{abstract}

\section{Keywords}

Mobile journalism, fake news, media convergence, social responsibility, Pakistan's and Ghana's news media.

\footnotetext{
${ }^{1}$ Corresponding author:

Sadia Jamil, University of Queensland, St Lucia Qld 4072, Australia.

Email: sadia.jamil@ymail.com
} 


\section{Introduction}

Technology has always been at the forefront of newsgathering and the journalistic process. The last century has seen audio, visual, and digital innovations contributing greatly to changing the way journalists think about and perform their routine work (Lasorsa et al., 2011). With the advent of new media technologies, the possibility for journalists to create, modify, and share content with others by using relatively simple tools has actually transformed the way journalism is practiced (Gambarato \& Alzamora, 2018; Pavlik, 2001). Particularly, the new technologies of mobile phone equipped with features of phone camera, sound recording, Internet access and instant messaging have resulted in the rise of mobile journalism around the globe (Gambarato \& Alzamora, 2018; Westlund, 2013). Mobile phones are revolutionizing journalism practice by transforming traditional patterns of news gathering and production as the reporters now use mobile phones to inform and to give live picture from the field without using broadcast systems (Gambarato \& Alzamora, 2018; Jokela et al., 2009). Evidently the mobile devices have reformed the newsroom environments by introducing new means to connect with the audience and to communicate with other journalists within the same place (Mabwezara, 2009; Nicole, 2014).

Like many other countries, Pakistan and Ghana have experienced mobile phone explosion and easy access to the Internet. For instance, Ghana has an estimated population of 29 million, yet the country has 34.57 million mobile phone users (Zanney, 2018). Whereas, Pakistan has a total population of approximately 204.60 million and the number of 3G and 4G users in Pakistan has reached to 55.47 million and approximately 150 million Pakistani people use mobile phones (World Population Review, 2019; Yousufzai, 2018). The penetration of mobile infrastructure has revolutionised Pakistan's and Ghana's journalism landscapes so the working journalists, being part of mobile-laden media ecosystem, are more well-equipped and connected for rapid production and dissemination of news especially in rural and remote areas of both countries (Ahiabenu et al., 2018; Umair, 2016; Zanney, 2018). Despite these positive implications of mobile journalism, the use of mobile phones and cameras for news reporting by journalists has raised concerns regarding the authenticity and credibility of the news content in Pakistan and Ghana both (Ahiabenu et al., 2018; Umair, 2016).

There are significant international studies on fake news (Ahiabenu et al., 2018; Iretton \& Posetti, 2018; Levinson, 2016; McNair, 2017) and mobile journalism practice (Bardoel \& Dueze, 2001; Bivens, 2008; Cameron, 2011; 
Nicole, 2014; Stephen, 2009; Umair, 2016; Westlund, 2008, 2013). However, there is a dearth of studies that offer qualitative analysis about the role of mobile journalism in reshaping news production process and the ways it aids in promoting fake news in Pakistan and Ghana. Therefore, drawing on the media convergence and social responsibility theories, this study fills this gap in literature by offering insights into three objectives, namely: (i) to study how the proliferation of mobile phone has altered the news production and distribution process in Pakistan and Ghana; (ii) to analyse the ways practice of mobile journalism among professional journalists are promoting the trend of fake news in Pakistan's and Ghana's news media; (iii) to investigate whether professional journalists receive training for mobile journalism and news verification in both countries.

\section{Theoretical framework: Media convergence and social responsibility theories}

Media convergence is concerned with the coming together of two or more distinctive perspectives of the media industry due to technological innovations (Dominick, 2011; Grant \& Wilkinson, 2009; Jenkins, 2006; Kalamar, 2016). In media studies, convergence advances analysis of the blurring boundaries between the media and telecommunications. The theory highlights the fusion of different tools and equipment for news production and distribution because it is the coming together of the media, telecommunications and computer industries (Grant \& Wilkinson, 2009). Singer (2004) posits that media convergence is 'some combination of technologies, products, staff and geography among the previously distinct provinces of print, television and online media'. It is also considered as being beyond technological shift because it has not only transformed the relationship between existing technologies, but it has also altered the relationship between existing media industries, markets, genres and audiences (Jenkins, 2006).

Though it has been established that media convergence is about fusion of varying but inter-connected components in the media industry, the exact components that are fused are considered from various dimensions (Dominick, 2011; Grant \& Wilkinson, 2009; Jenkins, 2006; Kalamar, 2016). The fusion of distinct but interwoven media features (Garcia, 2006) can be technological, ownership/economic, content, collaboration and operational. Technological convergence is the fusion of tools and equipment for news production and distribution (Grant \& Wilkinson, 2009), ownership/economic convergence is about the concentration of media companies due to economic reasons 
(Herkman, 2012; Lawson-Border, 2006) and content convergence has to do with the designing of a common content for different media including newspapers, radio, TV and online (Jenkins, 2006). Also, operational convergence occurs when a common newsroom is used for different media organisations (Garcia \& Carvajal, 2008), and collaboration or cooperation convergence happens when different media organisations cooperate with one another such that they both use a common entity in the course of news gathering and production (Deuze, 2004).

While there are various forms of convergence, this study is hinged on technological convergence. This is also known as production convergence (Cooke, 2005) and it is of much relevance to this study because it is about how technical design and functionality effectively interoperate in a device (in the context of this study mobile phone) for gathering and dissemination of news (Jenkins, 2006). Thus, technical design entails the fundamental set up necessary for digital content transportation whereas functionality encompasses accessibility. Technological convergence entails the merging of the functions of different gadgets into a device. For instance, beyond being used for phone calls and text messages, a smartphone is also used by journalists for recording audio and visual contents, compose news stories and send the packaged news to editors for review and/or broadcast to different sources within a short time.

Technological convergence has simplified news production and has facilitated accelerated news distribution (Dominick, 2011; Drula, 2015; Jenkins, 2006; Kalamar, 2016). As a result, journalists have changed their traditional pattern of news gathering and dissemination. For instance, the photo journalists can shoot, edit and send digital pictures to their editors on their smartphones without processing pictures in the darkroom and printing and distributing them physically. Editors can access stories from reporters and broadcast before the reporters get to the newsroom from the location of an event. Online newspapers can break stories as well as distribute news stories before traditional newspapers go into production due to technological convergence.

Convergence scholars agree that media convergence has transformed the journalism industry, especially news production and dissemination, in many countries (Dominick, 2011; Drula, 2015; Garcia \& Carvajal, 2008; Herkman, 2012; Jenkins, 2006; Kalamar, 2016; Lawson-Border, 2006) and Pakistan and Ghana are no exceptions. It has led to the adaptation of mobile journalism practices that has reshaped the media landscape and resulted in an increased speed in news production and distribution, more audience interaction, cut down on cost of media operations and a lifeline to declining newspaper circulation 
and sale (Garcia \& Carvajal, 2008). While mobile journalism has made the journalists' work easier and faster, they have also put a question mark on the authenticity and reliability of the news they report. And it is contended that mobile journalism as an outcome of technological convergence has given to the proliferation of fake news. This proliferation stems from the fact that journalists are not professional in their conduct and their news reports lack accuracy and truthfulness in countries like Pakistan (Umair, 2016) and Ghana (Ahiabenu et al., 2018). They are apathetic towards the huge negative impact of fake news to democratic political systems in societies. Beyond freedom of expression, democracy is most importantly about responsibility for the right to free expression. Thus, being guaranteed the right to freedom of expression does not mean professional journalists must produce fake news. Rather, the guaranteed freedom should be enjoyed responsibly with the development of the society in mind.

Therefore, in addition to the media convergence theory, this study also uses the social responsibility theory that emphasizes journalists' adherence to professional standards of objectivity, truthfulness, accuracy and impartiality. The theory supports the notion of freedom with responsibility that requires individual journalists and media organizations not only to report facts with truthfulness, but also to provide deeper and unbiased interpretations of news stories in the public's interest. Thus, the theory attempts to buttress journalistic standards and their roles in any society for accomplishing broader objectives of democracy and development. Drawing on the principles of social responsibility theory, many countries worldwide, have devised journalistic codes of ethics (Baran \& Davis, 2005). Code of ethics sets a frame work for the journalists within which they can perform their routine jobs professionally, and thus can be viewed as a self-regulatory mechanism for responsible journalism (Encabo, 1995). It serves the public interest by ensuring dissemination of truthful, impartial, accurate information and protection of other basic human rights such as freedom of speech; protection of privacy, reputation and religious feelings (Baydar, 2008; Jamil, 2017).

The theory avers that the 'press is not free if those who operate it behave as though their position conferred on them the privilege of being deaf to ideas which the processes of free speech have brought to public attention' (Baran \& Davis, 2003). Thus, the media are expected to be responsible for progression of democratic values and principles in any democratic society.

Hence, this study draws on two strands of theoretical frameworks: media convergence theory and social responsibility theory. Media convergence, 
specifically technological convergence, is used in this study to analyse the use of mobile phones in news gathering and news dissemination process in Pakistan and Ghana. It is also used in authors' assessment of the proliferation of fake news in the two countries and it justifies the need to investigate the training given to journalists in the countries so as to be able to detect fake news in the prevailing disruptive era. Furthermore, this study has used social responsibility theory as the second strand of theoretical framework to analyse whether the growth of mobile journalism has facilitated or affected the practice of responsible journalism through providing the public unverified or fake news in Pakistan and Ghana.

\section{Literature review Media landscape in Pakistan}

Pakistan's media is quite vibrant in Southeast Asia. However, the country's media operates under the competitive authoritarianism. Independent media exists with the constitutionally protected rights of freedom of expression and access to information under the Articles 19 and 19 (A) of the Constitution of Pakistan (1973). However, the ruling authorities use different mechanisms to suppress the voice of media through constitutional manipulations, financial incentives, taxes, the selective allocation of government's advertisements and stringent media laws. Journalists are also banned, imprisoned and harassed by the government being critical of its performance. Thus, there is always a tension between the government and the media outlets (Jamil, 2017; Riaz, 2010).

Pakistan's print media ecology can be characterised as pluralistic and competitive. It reflects ethnic, linguistic and class division. There are almost over 18 major Urdu-language's newspapers circulating across Pakistan. The Urdu print media is popular and enjoy a wide range of readership or viewership, especially in the middle class of the society. There is an existence of both conservative and liberal strands within the Urdu-language's newspapers. As far as English print media is concerned, there are over approximately 12 mainstream Englishlanguage newspapers in the country. And they have a very low mass readership than the Urdu-language newspapers (Khan \& Aziz, 2017). The reason behind the lesser readership of English-language newspapers is the linguistic barrier and Pakistan's less literacy rate. However, the English-language media has a greater leverage on policy makers, politicians, elite class, civil bureaucracy, industrialists and professionals (Riaz, 2010; Siraj, 2009).

The vernacular media also exists in provincial and regional languages including Sindhi, Punjabi, Baluchi, Pashtu, Saraiki, and Kashmiri languages 
(International Media Support, 2009). The cross-media ownership dominantly characterise Pakistan's mainstream media with the influence of major media groups such as Jang Group, Herald Group, Nawa-e-Waqt Group, Business Recorder Group, ARY digital network, and Lakson Group.

Furthermore, in the past, there used to be only one state-owned television channel known as Pakistan Television Corporation (PTV). However, in the last ten years, there has been a proliferation of private television news channels in Pakistan. At present, there are over 80 local television channels available to the Pakistani viewers via cable and satellite, along with many other international television channels. This mushrooming of satellite television news channels has helped to reduce the information vacuum and the state monopoly on the broadcast media. The growth of private television news channels has positively implicated in the culture of political discussions, which is imperative to increase the public's awareness in Pakistan (Riaz, 2010).

In terms of the 'sources of revenue', the print media (either in Urdulanguage or English-language) rely on approximately less than 35 per cent of the government's advertisements, apart from the advertisements given by multinational companies. On the other hand, private television channels' and radio stations' owners mainly derive their revenue from commercial advertisements given by multinational companies.

Apart from local Press Council, there are five main media associations in Pakistan, namely: All Pakistan Newspapers Society (APNS), The Council of Pakistan Newspaper Editors (CPNE), Pakistan Federal Union of Journalists (PFUJ), Pakistan Press Foundation (PPF), and the Association of Television Journalists (ATJ). Each province has its own journalist union as well. For instance, journalists in Karachi have their union called as Karachi Union of Journalists (KUJ). There are two national news agencies currently in operation including Pakistan Press International (PPI) and the Associated Press of Pakistan (APP). Foreign media correspondents from CNN, BBC, Al-Jazeera, Voice of America do report from Pakistan's various major cities for the coverage of local news.

\section{Media landscape in Ghana}

Ghana has a liberal and vibrant media landscape under the Fourth Republic due to lessons learnt from its post-independence political and press histories. It is among the African countries with best press freedom ratings. The 1992 Constitution has been rated as the best so far in comparison with previous constitutions because its provisions on rights/freedoms of the citizens and the press are explicit and elaborate (Owusu, 2012). The twelve Articles under 
Chapter 12 of the 1992 Constitution are dedicated to provisions on freedom of the press. As a result, journalists in Ghana enjoy double freedoms: their rights to free expression in Article 21 (e) and their right to freedom of the press in Article 162 (1). Freedom of the press is guaranteed by the constitution and it explicitly forbids censorship, government control and harassment of editors, publishers and journalists. The constitution mandates the formation of an independent regulatory body, the National Media Commission (NMC), to oversee the functioning of the press and outlines the duties of the commission.

The repeal of the Criminal Libel and Sedition law in 2001 is considered as another success of the Fourth Republic in ensuring that the press is free. This is because it has 'brought a measure of respite to journalists, particularly those in the private media' (Owusu, 2012). However, in place of decriminalising the libel and sedition laws, there had been cases where huge fines are slapped on the media as compensation for damages in civil libel cases and such instances have negative implications for the promotion and the protection of freedom of speech and of press in Ghana. Also, the country just passed the Right to Information Law and it is seen as another attempt to give more freedom to the media. This is because it is expected that the law will give the media more access to information.

Before and just after the Fourth Republic, private print media existed but the electronic media were monopolised by government. This has changed in the last fifteen years because in the spirit of the 1992 Constitution, many private electronic and online media outlets have been established. According to National Communication Authority (2015), 412 radio outlets, 54 television stations and 136 newspapers are in Ghana and currently, the statistics are higher especially for the electronic and online media outlets. All the traditional and online newspapers are published in English language but the electronic media and their web-sites broadcast in English or Ghanaian languages. The elitist, therefore, patronise the newspapers and English-language news channels whiles the middle and lower class patronise media outlets that use the Ghanaian languages, especially Twi, due to language barrier.

Ghana has exhibited a liberal approach to foreign media. Representatives from Associated Press (AP), British Broadcasting Corporation (BBC), Cable News Network (CNN), Aljazeera and other well-known foreign channels are resident in the country. Foreign newspapers like New York Times and Washington Post can be accessed high class hotels. However, with the exception of content from $\mathrm{BBC}, \mathrm{CNN}$ and Aljezeera, content of other foreign media is limited to the elitist due to cost implications and language barrier. Thus, some free to air channels broadcast content from these foreign channels to their viewership. 


\section{Mobile journalism, the changing pattern of news production and the rise of fake news: The rationale to compare the cases of Pakistan and Ghana}

In developing countries, the rate of information communication technology development over the past two decades has been breathtaking, to say the least. These developments have affected all aspects of life and work. As a result, it is a generally accepted notion that new communication technologies have had, and will continue to have a significant impact on how media organisations and the public communicate, including the way journalism is produced and practised in different countries of the world (Ireton \& Posetti, 2018; Umair, 2016). For this study, two developing countries from Africa and South Asia have been chosen, namely: Pakistan and Ghana.

The cases of Pakistan and Ghana are very interesting because Ghana ranks 113 and Pakistan ranks 148 in the UN's Global ICT Index of 2017 (International Telecommunication Union, 2017). This implies that Ghana's ICT progress is much higher as compared to Pakistan. Despite a good progress towards ICT development, the number of mobile phone users in Ghana is 34.57 million (Zanney, 2018), which is very less as compared to Pakistan. According to Pakistan Telecommunication Authority Statistics (2018), the number of 3G and 4G users in Pakistan has reached to 55.47 million and approximately 150 million people use mobile phones, despite the country's very slow progress towards ICT development (Yousufzai, 2018). Besides, Ghana has 10.11 million active Internet users (Zanney, 2018) while that of Pakistan is 44.61 million (Farooq, 2019).

Moving beyond ICT related statistics, both countries have different levels of media freedom and censorship as well. The media landscape of Ghana is most liberal and the Ghanaian press is freest in Africa (Nayko, 2016; Reporters Without Borders, 2019) but that of Pakistan is not liberal and the Pakistani press is not free as compared to other countries in South Asia (Jamil, 2017; Reporters Without Borders, 2019). Also, censorship is prohibited in Ghana (Constitution of Ghana, 1992), but media content is regularly and heavily censored by Pakistan Media Regulatory Authority, the country's government and military/ or intelligence agencies (Reporters Without Borders, 2019). As a result, Ghana is favourably rated by Freedom House and Reporters Without Borders than Pakistan (Freedom House, 2019; Reporters Without Borders, 2019).

Markedly, Pakistan and Ghana are two very different countries from South Asia and Africa respectively because they have different levels of population, ICT development, mobile subscribers, media freedom and censorship. However, still both countries have commonly witnessed an increase in the journalists' use of mobile phones in their routine work, resulting in the growing culture of fake news. 
With regard to this, a few recent studies and reports reveal that both countries have experienced mobile phone explosion that has resulted in the rise of mobile journalism. These recent reports and studies indicate that the growing practice of mobile journalism has altered the way journalism is produced in Pakistan (Umair, 2016; Weiss, 2019) and Ghana (Ahabienu et al., 2019; Endert, 2018; Sey, 2011). Also, some studies have shown that mobile journalism has fostered a rapid rise in the culture of fake news in both countries (Ahabienu et al., 2019; Umair, 2016). However, there is no study that offers comparative and qualitative insights into how mobile journalism has transformed the process of news production in African and South Asian developing countries. Hence, it is in this light that this study seeks to comparatively investigate the interplay between the rise in mobile journalism and its implications for the news production and distribution process and news authenticity in two countries of Africa and South Asia (i.e. Pakistan and Ghana).

\section{Methods}

Drawing on the media convergence and social responsibility theories, this study employs the qualitative methods of document review and in-depth interviews in order to investigate three research questions: (i) What is the impact of the proliferation of mobile phone on news production and distribution process in Pakistan and Ghana? (ii) How the practice of mobile journalism among professional journalists is promoting the culture of fake news in Pakistan's and Ghana's news media? (iii) Do journalists receive training for mobile journalism and news verification in both countries? Specifically, data triangulation is used in this study. Thus, qualitative data from document review and in-depth interviews have been used to interpret, clarify and validate the findings.

Using purposive sampling ${ }^{1}$, this study includes 15 in-depth interviews (faceto-face) of Pakistani male and female journalists, who work in the country's mainstream and most influential media organizations ${ }^{2}$, and who are also

${ }^{1}$ Purposive sampling refers to the 'selection of certain groups or individuals for their relevance to the issue being studied' (Gray et al., 2007). The purposive sampling has been chosen so as to ensure the representation of media monitoring officers from Ghana and Pakistan and working journalists from the selected mainstream media organizations in Pakistan.

2 This study includes 15 working journalists from 15 media organizations in Pakistan including: nine television news channels (i.e. SAMA News, Geo News, ARY News, Express News, Dunya News, Ab Tak News, AAJ News, Channel 92, Pakistan Television Corporation); three English-language newspapers (Daily Dawn, The News International, Express Tribune); three Urdu-language newspapers (Daily Jang, Daily Express, Nawa-e-Waqt). 
members of media monitoring associations including: All Pakistan Newspapers Society (APNS), Council of Newspapers Editors (CPNE), and Association of Television Journalists (ATJ). For Ghana, four current senior officers from media monitoring organisations, National Media Commission (NMC) and Ghana Journalists Association (GJA), and two former senior officers of the monitoring organisations (who are currently editors of leading mainstream media organisations) have been interviewed ${ }^{3}$. In order to ensure the privacy of interviewees, the Pakistani interviewees' names have been replaced with numbers (ranging between 1 and 15) and the Ghanaian interviewees' names have been replaced with alphabets (ranging between A and F).

Moreover, this study uses thematic analysis ${ }^{4}$ to analyse data gathered from the in de-depth interviews. There are three key themes that have been derived from the research questions of this study, precisely: (i) proliferation of mobile phone and its impact on news production and distribution in Pakistan and Ghana, (ii) mobile journalism and the thriving culture of fake news in Pakistan and Ghana, (iii) journalists' training for mobile journalism and news verification in Pakistan and Ghana. Hence, the next section discusses the results of this study.

\section{Results and discussion \\ Proliferation of mobile phone and its impact on news production and distribution in Pakistan and Ghana}

Mobile journalism is a growing practice that employs convergence of various devices in a device - a mobile phone. With the little passage of time, mobile journalism has been accepted in various international broadcasting channels to enhance their services as news providers, such as CNN, BBC and Al Jazeera. This study reveals that the proliferation of a mobile phone has also revolutionised journalism landscapes in Pakistan and Ghana as the working journalists, being part of mobile-laden media ecosystem, are more well-equipped and connected for rapid production and dissemination of news. This is in consonance with literature on media convergence (Dominick, 2011; Drula, 2015; Garcia \& Carvajal, 2008; Herkman, 2012; Jenkins, 2006; Kalamar, 2016; Lawson-Border,

${ }^{3}$ In this study, the main location of data collection in Pakistan was Karachi and in Ghana was Accra. In addition, the number of selected Pakistani interviewees is greater than Ghanaian interviewees because Pakistani news media is comprised of over 35 television news channels and over 50 newspapers in different local languages, which reflects a larger media landscape of Pakistan as compared to Ghana.

${ }^{4}$ Thematic analysis helps to classify data under relevant themes in order to interpret the various aspects of research topic (Boyatzis, 1998; Braun \& Clarke, 2008). 
2006). For example, a majority of the interviewed journalists (i.e. Pakistan: 13 out of 15; Ghana: 5 out of 6) view that the proliferation of mobile technology has altered the news production and distribution process. Interview findings suggest that the development of information and communication infrastructure in Pakistan and Ghana have played a crucial role in transforming the traditional forms of news production and dissemination in both countries. The introduction of 3G and 4G mobile technologies has fostered the use of smartphones for news gathering and reporting. This is an affirmation of the main relevance of technological convergence in the media industry as noted by Grant and Wilkinson (2009), Jenkins (2006) and Singer (2004).

This study highlights that big television news channels use large crews and heavy equipment (such as OB Vans and broadcasting systems) in addition to using mobile devices for news production and distribution. Majority of middle to small-scale media organizations in both countries substantially rely on smartphone coverage of events because of these four common reasons: (i) easy mobility, (ii) fast production and distribution of news or information (through SMS, WhatsApp and e-mails), (iii) low cost (in terms of crew and equipment), and (iv) capacity for live transmission and break news in real time to audience (through Periscope and Face book live). This is in agreement with literature on the outcome of technological convergence on media operations (Garcia \& Cavajal, 2008; Jenkins, 2006). Beyond these common reasons, Pakistan's journalists' reveals that an increased accessibility to remote and conflict areas and better level of safety are additional reasons for their smartphone coverage of events.

Interviewees' responses highlight that mobile journalism has made the process of news production and dissemination much faster and less costly (See Grant and Wilkinson, 2009) as the Pakistani and the Ghanaian journalists both are able to produce and distribute news in no-time and without big outdoor broadcasting vans and satellite trucks. In this regard, a male journalist from a local television news channel in Pakistan and an editor of a national newspaper in Ghana respectively suggests:

'I would not say that the penetration of Information and Communication Technology Infrastructure (ICT) and an increased use of mobile phone technology have totally changed the journalism practice in Pakistan. Yes, there are certain notable changes in the process of news gathering, production and distribution. Journalists, working even in big media organizations that operate with rich resources, are now using mobile phones for information gathering $<\ldots>$ and they no longer rely only a satellite truck or OB Van and other heavy equipment for reporting'. (Interviewee number 6) 
'I think not only mobile journalism, but technology has enhanced journalism in Ghana. If I should take you back to history, you will realised that our coverage of news took place at the location of things that happen... and one has to be there physically to cover and go back to his or her office and write the story, present it to the news editors for publication. But with the advent of technology and social media platforms, it is possible to watch an event on Face Book live from even Tamale or Wa [northern part of Ghana] sitting right in the comfort of one's office in Accra [southern part of Ghana] to write the story. Hitherto you may have it when it is a live coverage by a TV station. Also, what is happening now is that most newsrooms are cutting down on cost. Therefore, media organizational rely on people who can provide them with the information on social media platforms $<\ldots>$ And the social media platforms and the Internet have become sources of information where without soliciting, information is posted and news houses pick those posts as news to publish or broadcast'. (Interviewee C)

When comparing the cases Pakistan and Ghana, this study highlights similarities on the cost cutting strategies of news organizations as media owners in both countries are reducing their staff and prefer mobile journalists (MoJo) who can perform multi-tasking of video shoot, editing and news distribution through their smartphone. Though many Pakistani journalists (i.e. 9 out of 15) think that the practice of mobile journalism has resulted in their financial insecurity and crises, and the Pakistani journalists from television news channels are suffering more as compared to those working in the country's newspapers. For instance, editor of an Urdu-language's newspaper in Pakistan says (Interviewee number 11), 'I call it the financial murder of journalists. News organizations cannot call any journalist a "redundant staff" just because of new ways of news production. Unfortunately, technology has some negative implications for journalists too'. Another common implication of mobile journalism is the use of social media information (as mentioned by the Ghanaian interviewee $\mathrm{C}$ above), which is resulting in a culture of fake news in both countries (See also Ahiabenu et al., 2018).

Thus, there is no uncertainty that mobile journalism is transforming the way news is gathered, packaged and distributed in Pakistan and Ghana. Particularly, in the case of Pakistan, the development of mobile phones with advanced multimedia features and Internet connectivity has brought new ways for journalists to live out their risky and challenging profession. News stories, photos and videos can be produced or even published straight from remote and risky conflict areas (such as Interior Sindh, Federally Administered Tribal Areas, Baluchistan and Khyber Phaktukhwa provinces), making the news production 
process safer, faster and more efficient. Despite these positive implications of mobile journalism, this study unpacks the rampant rise in the culture of fake news as an outcome of growing numbers of mobile journalists in Pakistan and Ghana. Hence, the next section addresses this aspect.

\section{Mobile journalism and the thriving culture of fake in Pakistan and Ghana}

Mobile journalism has transformed news production and dissemination process in many countries due to technological convergence and this is creating opportunities for independent journalists, citizen journalists and bloggers (Gambarato \& Alzamora, 2018). However, one major implication of the practice of mobile journalism is the rise of fake news trend (Grant and Wilkinson, 2009; Jenkins, 2006; Umair, 2016). As the technology is advancing, the use of mobile phones and cameras for live reporting and journalism have also questioned the authenticity of the news content being reported to the public. The authors believe that the use of mobile photos and video sharing on social media sites and other online platform has maximized the unauthenticity of incidents and news content. The growing trend of breaking news and live transmission has increased the competition between professional journalists, resulting in their reliance on the use of mobile devices for reporting. The videos and image with minimum quality and blurred videos are usually considered to be accurate. The videos and photos may be tempered or manipulated, or the content may be disseminated in such a way that it conveys half or wrong information (Ahiabenu et al., 2018; Ireton \& Posetti, 2018; Umair, 2016).

This study also highlights the Pakistani journalists generate news stories, images and videos that are often put on Internet instantly and without any verification of incidents and content. For example, when talking about the implications of mobile journalism, a male television news producer in Pakistan states:

'Pakistan's news organizations are inclined to recruit mobile journalists (MoJos) that is basically a cost-cutting strategy by minimizing the staff. Then, public has no idea how uploading of unverified information, rumours and manipulated videos on Internet and social media are affecting the societal peace and the integrity of journalism as an institution. Ironically, professional journalists also use videos and images received by the public and these are normally not verified $\langle\ldots\rangle$ I feel sad to say that the gate keeping process is weak in the Pakistani news media'. (Interviewee number 16)

Unlike the case of Pakistan, the interview data from Ghana suggests that the news content from media organisations (whether produced by journalists or 
citizen journalists) do not encourage fake news as they are verified during the gatekeeping stage of news production. Thus, only editors can disseminate news stories from their organisations, therefore; content from media organisations is verified by sub-editors and/or editors before dissemination. However, content from citizen journalists who are not liaising with any media organisation, do not go through any verification process because there is no gate keeping. For instance, in January 2019, the President of Ghana has condemned the killing of Ahmed Hussein-Suale (an investigative journalist) and has charged the police to investigate and punish the culprits on his twitter post. Some media organisations have picked the President's twitter post as a news item for their network without further investigation into the case. There are many other examples of the Ghanaian's media use of unverified information from citizen journalists, who gather and disseminate news using their smartphones. With regard to this, a senior officer associated with a local media monitoring organisation notes that:

'I don't think that mobile journalism, as you have defined, it is encouraging fake news. I think more specifically the issue of fake news is all about gate keeping. It is about gate keeping more than the use and facility of news generation $<\ldots>$ a citizen journalist, if he contributes through the main stream media, there is a gate keeping process where there is an editorial process, and so by the time the news is let out, somebody takes responsibility for the story and when push comes to shove that editor will come out and apologize for the error. So, that form of gate keeping is very fundamental to the issue...' (Interviewee A).

In comparison, the foregoing analysis shows that the news verification process is weaker at media organizations in Pakistan than in Ghana. This is because any content from media organisations in Ghana go through verification process before dissemination, except content from citizen journalists who are not associated with any media organisation. Despite a good level of news verification in the Ghanaian news media, the authors think that there is still space for the breeding of fake news in the country's traditional media outlets as Ahiabenu et al (2018) suggest that:

'It is important to stress that several media houses (in Ghana) rely on social media and online content in their news production processes. This situation poses a major risk since the use of social media and online content is now the norm in most newsrooms across the country. As a result, fake news is not only an online and social media occurrence since its influence on traditional media is now a reality'.

When analysing the case of Pakistan, as aforementioned, there is a lack of news verification and gate keeping rise that is fostering fake news culture 
and misguiding millions of Pakistanis news consumers. According to a senior journalist from an English-language newspaper:

'In many medium to small-scale Pakistani television news channels, reporters rely on their mobile phones for video shoot and sound recording. And at times, video images and sound recordings are not clear that can mislead the public about the actual facts of incident/s $<\ldots>$ Citizen journalists are actually more harmful for the journalism industry in Pakistan. For the sake of competition and breaking news, footages captured by citizens and information received by them are instantly broadcasted on television news channels without any verification. I would say that news verification process in newspapers is much better as compared to television news channels in Pakistan'. (Interviewee number 12)

In Pakistan, interviewed journalists' feedback reveals some more interesting facts regarding the growth of fake news trend. According to a senior news director of local television news channel:

'I do not see any difference between fake news and planted news. At times, we receive information from government's officials and political parties, and we are forced to on-air the news without any filtration or verification. We are compelled to broadcast the news regardless of the authenticity of provided information. This is called as news feeding $\langle\ldots\rangle$ So, it is not just mobile journalism that is fostering fake news trend in Pakistan, but one must recognize political pressures and safety threats that compel journalists to publish and broadcast misleading information'. (Interviewee number 9)

Similar to the case of Pakistan, in Ghana, there is also an increase in fake news culture from citizen journalism that is misinforming the media audience. A senior Ghanaian officer from a local media monitoring organisation posits that:

'More people are able to transmit information and the possibility of verification is lessened because of the availability of smartphones and social media. Therefore, a lot of fake news are going out... and in terms of occurrence, it is more with the mobile journalism than mainstream media...the fact is that it is becoming a trend now and more and more people who have access to the mobile phone so are able to distribute information' (Interviewee D).

Interestingly, almost all interviewees in Pakistan (i.e. 14 out of 15) and Ghana (i.e. 6 out of 6) also admit that media literacy rate is very low in both countries, so it is difficult for most news consumers to distinguish between credible news sources and fake news. Therefore, they suggest for introducing reforms in media laws, thereby to combat the menace of fake news that is potentially increasing because of journalists' and citizens' irresponsible practice 
of unverified information dissemination. Some Pakistani journalists, in this study, emphasize academic reforms for fostering media literacy and ethical mobile journalism practice. For instance, a female journalist from an Urdulanguage's newspaper states:

'There are no proper media literacy and journalists' training programs offered by local universities and media organizations, which I think is one of the major reasons for the rise of fake news trend $<\ldots>$ Mobile journalism is evolving in Pakistan and journalists do need training on how to maintain accuracy and ethics being a MoJo'. (Interviewee number 5).

By and large, this study has manifested that mobile journalism is causing an increase in the spread of fake news in both countries, and unfortunately very less is known about how much the Pakistani and the Ghanaian journalists are trained for news verification and mobile journalism. Therefore, the next section reflects on this point.

\section{Training for mobile journalism and news verification in Pakistan and Ghana}

Fake news has become a global phenomenon during the last couple of years. However, mainstream media organisations across the world are using different mechanisms to counter fake news. For example, mainstream US media organisations (such as The New York Times, the Washington Post and CNN) have not only trained their journalists to be on guard against fake news but also developed effective mechanisms to make sure fake news is filtered out from their news stream (McNair, 2017; Umair, 2016). Social media giants (like Facebook, Twitter and Google) are developing algorithms to identify and discourage fake news. And many international universities and media training organisations are investing in research projects to deal with the menace of fake news.

In this study, interview data reveals that all interviewees in Ghana and the majority of Pakistani journalists (i.e. 14 out of 15) are not formally trained for fake news detection and news verification process by their organisations or the monitoring organisation. However, all of the interviewed Pakistani and the Ghanaian news editors mention that they informally caution journalists to double-check their sources. In this regard, a senior news producer from a local television news channel in Pakistan suggests:

'The problem is journalists do not pay attention on the authenticity of news or images or videos received through their cell phones and they put it on-air immediately just for the sake of breaking news. And in many news channels, the information received by citizen journalists is broadcasted without verification. 
Unfortunately, the concept of gate keeping has damaged in Pakistan due to irresponsible practices of journalists and media organizations. And universities and media organizations are apathetic to train journalists on how to cross check information and how to act professional and responsible when practicing mobile journalism $<\ldots>$ Apparently, Ministry of Information is also not interested to bring some effective laws and regulations that help to deal with the trend of fake news'. (Interviewee number 11)

An editor in a newspaper organisation in Ghana also submits:

'I will be telling falsehood, if I tell you now that in my organisation, we have a deliberate policy to teach or to educate our journalists to check and verify their information before it is published. But what we have done is to continue to alert them and continue to ask the sub editors and news editors to check the sources to make sure that the source is verifiable'. (Interviewee $\mathrm{C}$ )

In Pakistan, the multiplication of media channels and the race for ratings has led the channels to promote sensationalism and the culture of breaking news without keeping in view news authenticity (Umair, 2016). The journalistic discipline that requires a reporter or a commentator to verify any hearsay or news before publicizing it has been relaxed in Pakistan. What has further helped the spread of the fake news trend is the ignorance of the Pakistani universities, media organizations and media monitoring organizations to train journalists for news verification and fact-checking in the country. On the other hand, in Ghana, journalists from media organisation race with citizen journalists to break news to their audience. However, still the gate keeping process for professional journalists allows citizen journalists to first break the news whether it is credible or fake content. This implies that fake news gets to audience without any filter that not only allow fake news to thrive but also misinform the citizenry.

The authors, therefore, suggest that the Pakistani and the Ghanaian news organisations and media monitoring organizations also need to follow the example of the developed world's media to improve news verification process for information gathered or disseminated through mobile devices and to counter the menace of fake news.

\section{Conclusion}

Media convergence has altered journalism landscape in many countries of the world. Peculiarly, technology related convergence, has given rise to mobile journalism practice that has resulted in many positive and negative implications for the quality of journalism in various contexts (Grant \& Wilkinson, 2009). Mobile journalism has unleashed ground-breaking forms of gathering and 
publishing news including increased speed of news dissemination and ability to reach a wider audience. These innovations in journalism profession have affected the traditional ways of verifying the news content. Thus, 'fake news (i.e. spreading falsehood, misinformation and disinformation in public discourse)' has now become part of the 'global news ecosystem', a situation that has implicated in the citizens' lack of trust not only in the news media but also, in key governance institutions and the way they consume news. There are growing concerns and calls on governments to step in to deal the challenges that come with the proliferation of fake news without necessarily restraining journalists' free expression, which is a key principle of democracy or undermining the progress of the use of technology in the news production cycle (Ireton \& Posetti, 2018; Levinson, 2016).

Given this background, this study highlights the positive implications of mobile journalism in Pakistan and Ghana such as easy mobility of journalists, fast and economical production of news and better safety level of journalists (in the case Pakistan). Nevertheless, it also reveals the growing trend of fake news that seriously increases the weight of social responsibility on professional Pakistani and Ghanaian journalists in terms of ensuring that fake news does not affect the quality of journalism and the public's right to know. This study suggests that Pakistan's media severely lacks the practice of gate keeping filtering news stories either gathered by mobile journalists (MoJos) or received by citizen journalists. What is apprehensive is the apathetic attitude of Pakistani journalists' unions and media owners both, who are not putting efforts to make the journalistic codes of conduct effective in practice, to adopt the use of algorithms that can filter fake news and to organize training programs for mobile journalists. Unfortunately, no efforts have been made by the Pakistani Ministry of Information to promulgate laws to counter the culture of fake news in the country. On the other hand, in Ghana, this study highlights the need for media monitoring organisations and other stakeholders to train journalists, especially citizen journalists, on fake news detection and news verification to ensure quality journalism.

This study unpacks that there are growing concerns among Pakistan's and Ghan's journalists regarding the growing trend of fake news spreading through mobile journalism. Journalists from both countries urge their respective governments to step in to tackle the challenges that come with the proliferation of fake news without necessarily curbing free speech, which is a key principle of democracy and very necessary to undermining the progress of the use of technology in the news production cycle. Last but not least, this study also emphasizes that journalists must receive the essential technical training required 
to use mobile devices for news purposes. These technical competencies must be accompanied by core journalism skills such as storytelling, corroboration, news veri cation and ethics and packaging content for mobile devices.

\section{References}

AHIABENU, K., OFOSU-PEASAH, G., \& SAM, J. (2018). Media perspective on fake news in Ghana. PenPlusBytes, 2nd May, 2018. Available from: http:// penplusbytes.org/wp-content/uploads/2018/05/FAKE-NEWS-STUDY.pdf

BAQI, N. (2018). There is more sensationalism in Pakistan than real news, claims Bilawal at World Economic Forum. Express Tribune, 24th January, 2018. Available from: https://tribune.com.pk/story/1616864/1-theressensationalism-pakistan-real-news-claims-bilawal-world-economic-forum/

BARAN, J. \& DAVIS, D. (2003). Mass communication theory. USA, Wadsworth Publishing Company.

BARAN, J. \& DAVIS, D. (2005). Mass communication theory. USA, Wadsworth Publishing Company.

BARDOEL, J. \& DEUZE, M. (2001). Network journalism: Converging competences of media professional and professionalism. Australian Journalism Review, 23, pp. 91-103.

BAYDER, Y. (2008). Setting up a journalistic code of ethics: The core of media self-regulation. Media Self-Regulatory Guide (OSCE). Available from: http:// www.osce.org./f

BIVENS, R. K. (2008). The Internet, mobile phones, blogging. Journalism Practice, 2, pp. 113-129.

BOYATZIS, R. E. (1998). Transforming qualitative information: Thematic analysis \& code development. Thousand Oaks, CA, Sage Publications.

BRAUN, V. \& CLARKE, V. (2008). Using thematic analysis in psychology. Qualitative Research in Psychology, 3(2), pp. 77-101. Available from: http:// www.tandfonline.com/doi/pdf/10.1191/1478088706qp063oa

CAMERON, D. (2011). Mobile journalism: A snapshot of current research and practice. In: A. Charles and G. Stewart, The end of journalism: News in the twenty-first century. Peter Lang Publisher, Switzerland, pp. 63-71.

COOKE, L. (2005). A visual convergence of print, television, and the Internet: Charting 40 years of design change in news presentation. New Media Society, 7, pp. 22-46.

DEAN, S. \& ILLOWSKY, B. (2010). Sampling and data: Frequency, relative frequency and cumulative frequency. Available from: https://www.saylor.org/ site/wp-content/uploads/2011/06/MA121-1.1.3-3rd.pdf 
DEUZE, M. (2004). What is multimedia journalism. Journalism Studies, 5(2), pp. 139-152. DOI: http://doi.org/c76frk

DOMINICK, J. R. (2011). The dynamics of mass communication: Media in transition. New York, McGraw-Hill Companies.

DRULA, G. (2015). Forms of media convergence and multimedia content-A Romanian perspective. Media Education Research Journal, 19883293.

ENCABO, M. N. (1995). The ethics of journalism and democracy. European Journal of Communication, 10(4), pp. 513-526.

ENDERT, J. (2018). Ghana's media in race to keep up with the times. $D W$ Academie, 6th December, 2018. Available from: https://www.dw.com/en/ ghanas-media-in-race-to-keep-up-with-the-times/a-46612139

FAROOQ, M. (2019). Active social media users in Pakistan grows by 5,7\%: Report. Available from: http://digitalrightsmonitor.pk/active-social-mediausers-in-pakistan-grow-by-5-7-report/

Freedom House (2019). Freedom and the media 2019: A downward spiral. Available from: https://freedomhouse.org/report/freedom-media/freedommedia-2019

GAMBARATO, R. \& ALZAMORA, G. (2018). Exploring transmedia journalism in the digital age. Hershey, IGI Global.

GARACIA, A., JOSE, A., \& CARVAJAL, M. (2008). Integrated and crossmedia newsroom convergence - two models of multimedia news production. Convergence: The International Journal of Research into New Media Technologies, 14(2), pp. 221-239. DOI: 10.1177/1354856507087945

GARCIA, A. (2006). Broadcast journalism in the age of digital convergence. Elche, Universidad Miguel Hern ndez.

GRANT, A. E. \& WILKINSON, J. S. (2009). Understanding media convergence. Oxford University Press.

GRAY, P. S., WILLAIMSON, J. B., KARP, D. A., \& DALPHIN, J. R. (2007). The research imagination: An introduction to qualitative and quantitative methods. New York, Cambridge University Press.

HERKMAN, J. (2012). Convergence or intermediality? Finnish political communication in the new media age. Convergence: The International Journal of Research into New Media Technologies, 18(4), pp. 369-384. DOI: http://doi. org/tkx.

IRETON, C. \& POSETTI, J. (2018). Journalism, fake news and disinformation. Available from: https://en.unesco.org/sites/default/files/journalism_fake_ news_disinformation 
International Telecommunication Union (2017). ICT Development Index 2017. Available from: https://www.itu.int/net4/ITU-D/idi/2017/index.html

JAMIL, S. (2017) Safety threats, impunity and professionalism: Journalists' dilemma in Pakistan. Journal of Sociology and Anthropology, 6, pp. 571-578.

JENKINS, H. (2006). Convergence culture: Where old and new media collide. Cambridge, Massachusetts, MIT Press.

JOHNSON, R. B. \& ONWUEGBUZIE, A. J. (2004). Mixed method research: A research paradigm whose time has come. Educational Researcher, 33(7), pp. 14-26.

JOHNSON, R. B., ONWUEGBUZIE, A. J., \& TURNER, L. A. (2007). Toward a definition of mixed methods research. Journal of Mixed Method Research, 1, pp. 112-134. DOI: $10.1177 / 1558689806298224$

JOKELA, T., HELIVA, J., \& TINA, K. (2009). Mobile journalist tool-kit: A field study on producing news articles with a mobile device. Proceedings of Mind Treck'09.

KALAMAR, D. (2015). Convergence of media and transformation of audience. Informatol, 49(3-4), pp. 190-202.

KHAN, T. \& AZIZ, I. (2017). The patchy world of Urdu newspapers. Dawn, 19th October, 2017. Available from: https://www.dawn.com/news/1364838/ the-patchy-world-of-urdu-newspapers

LASORA, D. L., LEWIS, S. C., \& HOLTON, A. E. (2012). Normalizing Twitter: Journalism practice in an emerging communication space. Journalism Studies, 13, pp. 19-36.

LAWSON-BORDERS, G. (2006). Media organizations and convergence: Case studies of media convergence pioneers. Rout ledge.

LEVINSON, P. (2016). Fake news in real context. Connected Editions, Inc.

MABWEAZARA, H. (2009). Between the newsroom and the pub: The mobile phone in the dynamics of every day mainstream journalism practice. Journalism, 12, pp. 692-707.

MCNAIR, B. (2017). Fake news: Falsehood, fantasy and fabrication in journalism. Abingdon, Oxon, Routledge.

National Communications Authority (NCA) (2015). National Communication Authority Fourth Quarterly Report: October-December, 2015.

NYARKO, J. (2016). Newspaper review show in the broadcast media space in Ghana: An exploratory qualitative study. Sage Open, 1-10. DOI: $10.1177 / 2158244016654952$

NICOLE, C. (2014). Revolutionizing the newsroom: How online and mobile journalism have changed broadcast journalism. The Elon Journal of Undergraduate Research in Communication, 5, pp. 1-3. 
PAVLIK, J. V. (2001). Journalism and new media. New York, Columbia University Press.

Reporters Without Borders (2019). 2019 World Press Freedom Index. Available from: https://rsf.org/en/2019-world-press-freedom-index-cycle-fear

SEY, A. (2011). New media practices in Ghana. International Journal of Communication, 5, pp. 380-405.

SINGER, J. B. (2004). 'Strange bedfellows? The diffusion of convergence in four news organizations. Journalism Studies, 5(1), pp. 3-18.

STEPHEN, Q. (2009). MoJo: Mobile phones in Asian region. Konard AdenauerStiftung, Singapore, pp. 1-65.

UMAIR, S. (2016). Mobile reporting and journalism for media trends, news transmission and its authenticity. Journal of Mass Communication Journalism, 6, pp. 323. DOI: 10.4172/2165-7912.1000323

WEISS, J. (2019). New technologies, citizen journalism changing Pakistan's media. International Journalists' Network, 29th February, 2019. Available from: https://ijnet.org/en/story/new-technologies-citizen-journalism-changingpakistans-media

WESTLUND, O. (2013). Mobile news: A review and model of journalism in an age of mobile media. Digital Journalism, 1(1), pp. 6-26.

WESTLUND, O. (2008). From mobile phone to mobile device: News consumption on the go. Canadian Journal of Communication, 33, pp. 443-463.

World Population Review (2019). Pakistan's population 2019. Available from: http://worldpopulationreview.com/countries/pakistan-population/

YOUSUFZAI, A. (2018). Pakistan now has 55.4 million mobile phone users with high-speed Internet. ProPakistani, 23rd June, 2018. Available from: https://propakistani.pk/2018/06/23/pakistan-now-has-55-4-million-mobilephone-users-with-high-speed-internet/

ZANEY, G. D. (2018). Jumia annual report 2018 launched in Accra. Government of Ghana, 20th March, 2018. Available from: http://ghana.gov. gh/index.php/media-center/news/4470-jumia-annual-mobile-report-2018launched-in-accra 